\section{Spatial analysis for stratification of priority malaria control areas, Mato Grosso State, Brazil}

\author{
Análise espacial na estratificação de áreas \\ prioritárias para o controle da malária \\ no Estado de Mato Grosso, Brasil
}

\author{
${ }^{1}$ Instituto de Saúde Coletiva, \\ Universidade Federal de \\ Mato Grosso, Cuiabá, Brasil. \\ 2 Escola Nacional de Saúde \\ Pública Sergio Arouca, \\ Fundação Oswaldo Cruz, \\ Rio de Janeiro, Brasil. \\ Correspondence \\ M. Atanaka-Santos \\ Departamento de Saúde \\ Coletiva, Instituto de Saúde \\ Coletiva, Universidade \\ Federal de Mato Grosso. \\ Av. Fernando Correa $s / n$, \\ Cuiabá, $M T$ \\ 78 090-060, Brasil. \\ slcs@terra.com.br
}

\begin{abstract}
The goal of this study was to stratify priority areas for malaria control in the State of Mato Grosso, Brazil, based on spatial analysis. The variables used were: Annual Parasite Index (API), Plasmodium falciparum/Plasmodium vivax ratio, population variation, number of families settled, and percent of deforested area. The Moran's I and Local Moran Test were applied, visualized with the Box Map and Moran Map, for 1986- 1991, 19921997, and 1998-2003. Box Map identified areas with high, low, and intermediate priority for control, and Moran Map identified municipalities with significant autocorrelation. In the high priority area, located in the North of Mato Grosso, malaria incidence decreased drastically despite the increase in the number of municipalities from the first to the last period. Other municipalities were added to the lower priority area, from the Southeast, Southwest, and Central-South of the State. The intermediate priority area was located along the border with neighboring States and municipalities classified as high and low priority. Spatial analysis showed the importance of the neighboring phenomenon between municipalities in defining priority areas, thus highlighting the technique's advantages for use in malaria control and surveillance.
\end{abstract}

Moran's I; Malaria; Communicable Disease Control; Spatial Analysis
Marina Atanaka-Santos 1

Reinaldo Souza-Santos 2

Dina Czeresnia 2

\section{Introduction}

In the late 1980s and early 1990s, the State of Mato Grosso, Brazil, witnessed a clear epidemic peak in malaria, reaching its maximum in 1992 with a total of 198,392 positive blood smears recorded, or an Annual Parasite Index (API) of 96.07 positive smears / 1,000 inhabitants. This trend then reversed, and the decline was constant, with a drop to 3.03 positive smears $/ 1,000$ inhabitants by the year 2003. However, the reduction was not homogeneous across the State, with areas of greater and lesser epidemiological relevance 1 .

Malaria is known as an eminently focal disease 2 whose distribution pattern is influenced by such factors as vector dispersal, human-vector contact, human mobility, economic production, and social reproduction of human hosts 3 , with no regard for political and administrative boundaries. Demarcation of areas for intervention according to risk distribution patterns is thus a key issue, especially for health system managers and professionals involved in malaria control programs.

In the 1980s, the Superintendency for Public Health Campaigns (SUCAM) stratified the Amazon Region according to risk areas for malaria, defining the so-called Priority Areas I and II 4. In its initial design, this stratification sought to prioritize efforts and resources according to the concentration, scattering, and spread of malaria cases 5 . 
One criterion now used to define priority control areas is the intensity of malaria transmission based on the API. This stratification, adopted by the Health Surveillance Secretariat of the Ministry of Health (SVS/MS), classifies areas as low risk (API $<10$ positive blood smears $/ 1,000$ inhabitants), medium risk (10 to 50 positive smears/1,000), and high risk $(>50 / 1,000) 6$. Malaria control programs have recommended constructing maps based on this classification in order to visualize areas aggregated according to risk level 7 .

Thus, the demarcation of priority control areas by mapping has become strategic for health services to both organize and implement surveillance practices. The correct localization and identification of these areas, especially regarding differentiated risks for malaria, orients the transfer of financial resources and control activities. However, although the criterion adopted by the SVS/MS allows spatial visualization of locations by risk stratification, it does not allow grasping the structure of spatial dependence in the disease's incidence. This stratification does not consider the possible existence of a spatial association between the occurrence of malaria in one municipality and that of its neighbor, i.e., between neighboring municipalities (counties) 8 .

The current study is intended to analyze the stratification of priority malaria control areas based on a spatial data analysis method that takes neighboring municipalities into account, and using data on malaria distribution for the State of Mato Grosso from 1986 to 2003.

\section{Methodology}

\section{Indicators and data source}

An ecological study was performed whose unit of analysis was the municipality (county), with the study area encompassing the State of Mato Grosso. The Brazilian Institute of Geography and Statistics, or National Census Bureau, provided the State's digital grids for the years 1991, 1997, and 2001 (IBGE: http://www.ibge.gov.br).

The selected malaria indicators were the API (number of positive blood smears/1,000 inhabitants) and the falciparum/vivax ratio. The records on positive blood smears for malaria reported from 1986 to 1997 were provided by the Statistics Division of the National Health Foundation/ Mato Grosso Regional Office; those from 1998 to 2002 were obtained from the Mato Grosso State Health Secretariat, stored in the Malaria Information System (SISMAL); those from 2003 were obtained from the Malaria Division of the Epi- demiological Surveillance Information System (SIVEP-Malaria) under the Health Surveillance Secretariat of the Ministry of Health. The choice was made to use positive blood smears by place of reporting due to the data's availability over the course of the three periods. The census data and population estimates obtained from the IBGE were used to calculate the API and population variation in the municipalities for each period. Population variation was expressed as the percent difference between the population estimates for the municipality at the beginning and end of each period.

The data from 1986 to 2003 were analyzed in three periods: 1986-1991 (P1), 1992-1997 (P2), and 1998-2003 (P3). As the criterion for defining the three periods, we used the turns in API trends in the State as presented in a study by Atanaka-Santos et al. 1. Calculation of mean API per period in each priority area was based on the sum of the annual APIs divided by six (the number of years per period), similar to the procedure used by Chaves \& Rodrigues 9 . Data on number of families settled by government programs in each municipality were obtained from the Mato Grosso State Statistical Yearbook 10,11,12,13,14, and for each period we calculated the mean number of families settled in each priority area. The percentages of the total area that had been deforested were obtained by municipality from 1992 to 2001 from the records provided by the State Environmental Foundation (FEMA; 2002), while those for 2002 and 2003 were obtained from the Mato Grosso State Statistical Yearbook 12,13. This study used the total percentage of deforested area in 1992, 1997, and 2003 for each priority area for $\mathrm{P} 1, \mathrm{P} 2$, and $\mathrm{P} 3$, respectively. This choice was based on the cumulative effect of deforestation; the use of the deforestation percentage for the year 1992 for P1 was due to the availability of data from that year forward.

\section{Spatial analysis}

We calculated the Moran's I 15 and the Local Moran Test only for the API values in the municipalities. Thematic API maps, Box Maps, and Moran Maps were constructed for each period in order to visualize priority control areas.

The Moran's I shows the existence of spatial autocorrelation, i.e., identifying when the observed API value in a municipality correlates with the values for neighboring municipalities. This index provides a single value, potentially varying from -1 to 1 , and is useful for studying regions as a whole.

In relation to the Local Moran Test, the Box Map was used first to identify spatially associated municipalities. The Box Map is constructed with 
standardized values (values of the attributes - API - subtracted from their mean and divided by the standard deviation), classified according to their position in relation to the quadrants in the Moran Scatterplot that receives a corresponding color when the map is generated 16 . Thus, according to their location in the Moran Scatterplot quadrants, the municipalities were classified according to clusters of homogeneous municipalities called Quadrant 1-Q1 (+/+) and Quadrant 2-Q2 (-/-) for areas with positive spatial association, and Quadrant 3 - Q3 (+/-) or Quadrant 4-Q4 $(-/+)$ for areas with negative spatial association.

Q1 (+/+) indicates a municipality with a positive standardized API value and a positive mean for the standardized values of neighboring municipalities, i.e., both values are positive; Q2 (-/-) indicates municipalities with negative standardized API and negative mean for the standardized values of neighboring municipalities, i.e., both values are negative. Thus, Q1 and Q2 indicate areas with positive spatial association, considering that the given municipality has neighbors with similar values 16 .

Q3 (+/-) includes municipalities with positive standardized API and negative mean for the standardized values of neighboring municipalities, while Q4 (-/+) includes municipalities with negative standardized API and positive mean standardized values for neighboring municipalities. Neither Q3 nor Q4 follow the global trend and indicate areas of negative spatial association, considering that there are neighbors in the same area with distinct values. Such regions are considered transition areas between the two spatial regimes, and in this study Q3 and Q4 are located by way of the municipalities from Q1 and Q2 16.

Based on the map generated by Box Map, three different malaria control priority areas were defined:

- High priority: municipalities aggregated in Q1 $(+/+)$;

- Low priority: municipalities aggregated in Q2 (-/-);

- Intermediate priority: municipalities aggregated in Q3 (+/-) and Q4 (-/+).

The Moran Map was constructed to visualize the interior of each priority area identified by the Box Map, areas with statistically significant spatial autocorrelation, and the locations with the most pronounced spatial dependency. The Moran Map represents the Local Moran Index, whereby municipalities are classified in four quadrants or as statistically non-significant 16 . For this study, each geographic cluster with statistically significant spatial autocorrelation inside each quadrant (Q1, Q2, Q3, and Q4) identified by the Box Map was termed a cluster.
For spatial statistical analysis, the free access software TerraView 3.0.3 was used (Instituto $\mathrm{Na}$ cional de Pesquisas Espaciais, Brasil; http:/ /www. dpi.inpe.br/terraview). The maps were generated with MapInfo Professional 7.0 (MapInfo Corporation, New York, USA).

\section{Results}

API showed a downward trend from the first period $(\mathrm{P} 1)$ to the last (P3), and there was an increase in municipalities with no report of positive blood smears, especially in P3. Based on the risk classification criteria used by the Health Surveillance Secretariat of the Ministry of Health (SVS/MS), we identified 17 high-risk municipalities $(17.89 \%$ ) (API > 50/1,000 inhabitants) in P1, $21(16.67 \%)$ in P2, and 4 (2.88\%) in P3. In addition, 78 (82.11\%) municipalities in P1, 105 (83.33\%) in $\mathrm{P} 2$, and 135 (97.12\%) in P3 showed API < 50/1,000 inhabitants, classified as intermediate or low risk according to the SVS/MS stratification. Southeast and Central-South Mato Grosso had the municipalities with no reports or with API $<10$ positive blood smears/1,000 inhabitants in the three periods (Figure 1).

In P1, all municipalities classified as high risk of transmission were located along the borders with the States of Pará, Amazonas, and Rondônia, except for the municipalities of Juruena (in the far West of the Mato Grosso) and Luciara (far Northeast). The same pattern held for P2, with a decrease in high-risk municipalities along the border with Rondônia. In P3, of all the high-risk municipalities, 3 were located in the far West of Mato Grosso, bordering on or near the State of Rondônia, and one (Feliz Natal) was located in the Central region of the State (Figure 1).

The Moran's I of API was $0.28(\mathrm{p}=0.01) ; 0.39$ $(\mathrm{p}=0.01)$, and $0.30(\mathrm{p}=0.01)$ from 1986 to 1991 (P1), from 1992 to 1997 (P2), and from 1998 to 2003 (P3). These values indicate a spatial correlation between the municipalities and their neighbors, with an increase in its strength from the first to the second period and a slight reduction by the third period. In mapping the API values (Figure 1), we observed heterogeneous malaria distribution in the State and specific local-level transmission dynamics that can be seen in the Local Moran, visualized using Box Map.

\section{Highest priority control area}

The municipalities located in the high priority area for malaria control according to Box Map showed a mean of 638.81 positive blood smears / 1,000 inhabitants in P1; 263.88 in P2; and 
Figure 1

Annual Parasite Index (API) distribution in the municipalities (counties) of Mato Grosso State, Brazil, 1986-2003.

1a) API: $1986-1991$

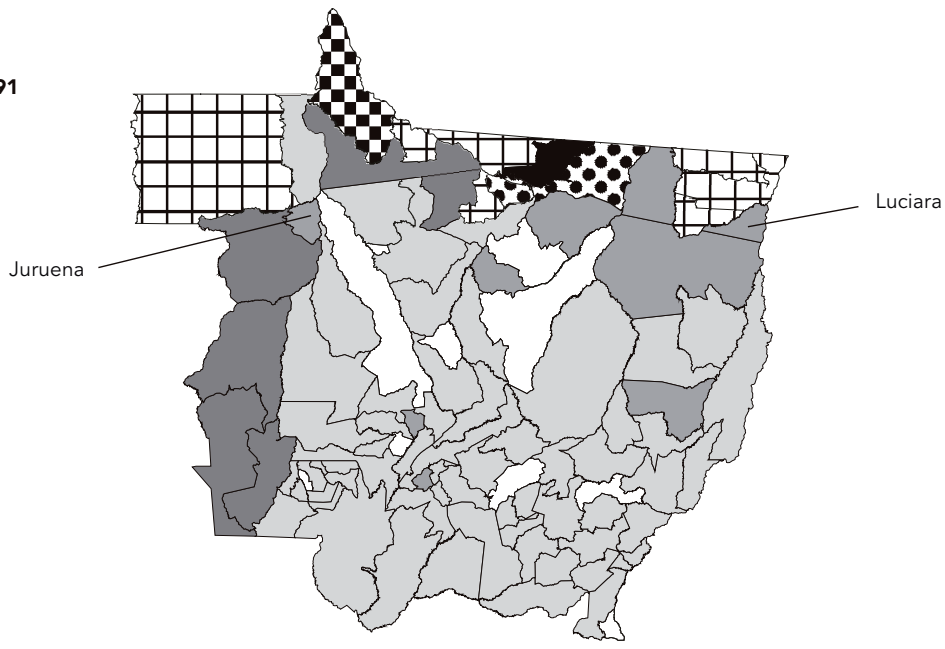

1b) API: 1992-1997

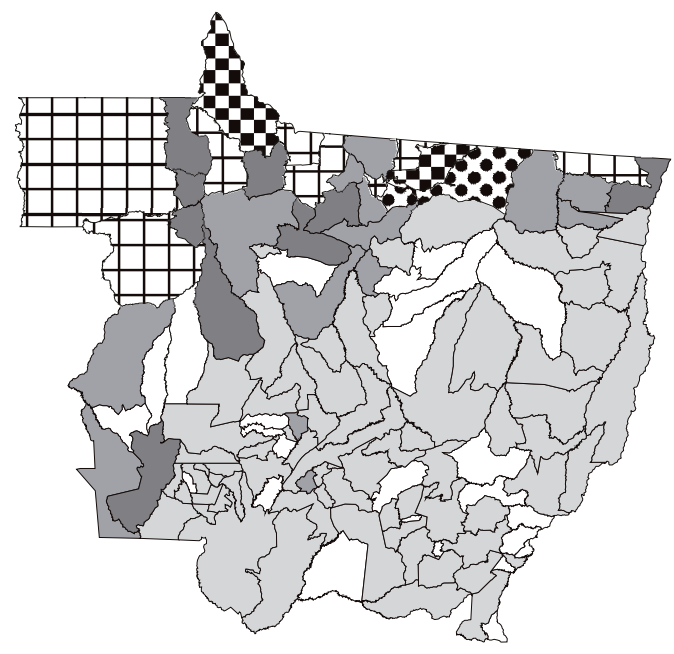

High risk

(2) AP: 1992-1997

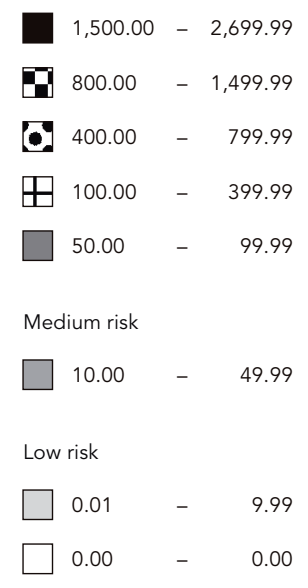

1c) API: $1998-2003$
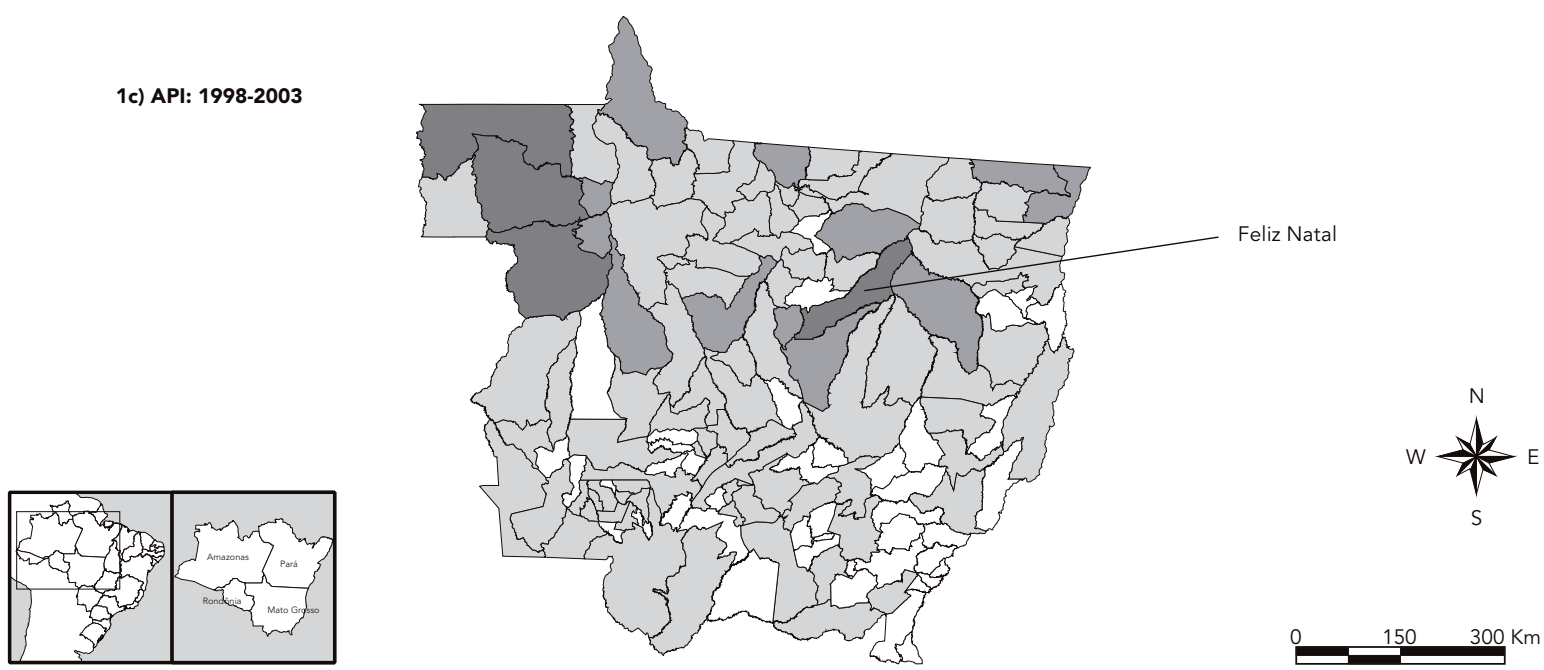
22.82 in P3. Despite the dramatic decreases in API from one period to another, especially from the second to the third, there was an increase in municipalities with priority Q1 $(10.53 \%$ of the municipalities in the State in P1, $14.29 \%$ in P2, and $19,42 \%$ in P3) and thus in the size of the high priority area from P1 to P3, with particular emphasis on the municipalities of Alta Floresta, Apiacás, Guarantã do Norte, Paranaíta, Peixoto de Azevedo, and Santa Terezinha, which remained in the high priority area during all three periods. In the last period there was a clear shift of the high priority area towards the Central region of the State (Figure 2).

In this area, during P1 falciparum malaria predominated (P.falciparum/P. vivax ratio $=1.07$ ); in P2 e in P3 there was a reduction in falciparum malaria, with a predominance of vivax ( $P$. falciparum/P. vivax ratio $=0.83$ and 0,24 , respectively). Another important variation was the intense population growth in $\mathrm{P} 1$ (51.58\%) and a reduction in the subsequent periods $(10.14 \%$ in P2 and $18.16 \%$ in P3). There was an increase in the mean number of families settled per municipality in the latter two periods. The total area deforested in Q1 was smaller than priority area Q2, larger than Q4, and similar to Q3 (Table 1).

Among the municipalities identified as high priority, the Moran Map showed that the proportion of municipalities with statistically significant autocorrelation increased from $5(50.00 \%)$ in P1 to $10(56.56 \%)$ in $\mathrm{P} 2$ and decreased to 6 (22.22\%) in P3. These municipalities with a pronounced API in relation to the neighboring municipalities in the three periods were located predominantly along the border with the States of Pará, Amazonas, and Rondônia (Figure 3). In P1, only one cluster of municipalities was identified with statistically significant autocorrelation.

In P2, the Moran Map detected two clusters (Cluster 1 and Cluster 2) inside high priority areas. Cluster 1, located in the Central-North of Mato Grosso, consisted of the same statistically significant municipalities detected in $\mathrm{P} 1$, except for Paranaíta, and with the addition of Nova Guarita (which had split off from Terra Nova do Norte) (Figure 3a). Cluster 2, located in the Northwest of Mato Grosso, consisted of Paranaíta plus Apiacás, Cotriguaçu, Nova Bandeirante, and Nova Monte Verde (Figure 3b). In P3, only one cluster stood out, consisting of 6 (22.22\%) municipalities, located in the far Northwest of the State (Figure 3c).

\section{Low priority control area}

Based on the Box Map, we identified more municipalities grouped in what were considered low priority control areas (Q2), located in the Southeast, Central-South, and Southwest of the State. There was also a decrease in API from 3.57 positive blood smears / 1,000 inhabitants in P1 to 2.11 in P2 and 0.46 in P3. There was a gradual drop in the number of municipalities classified as low priority from one period to the next $(77.89 \%$ in $\mathrm{P} 1$, $73.81 \%$ in P2, and $61.31 \%$ in P3). The decrease in the total size of the low priority area resulted from the shift of the high and intermediate priority areas to the Central region of the State (Figure 2).

The low priority area had a higher population growth rate in P1 (17.89\%), decreasing to $8.96 \%$ in $\mathrm{P} 2$ and $5.53 \%$ in P3. This growth rate was lower than the mean for the municipalities in the high priority area. The $P$. falciparum/P. vivax ratio was 0.59 in P1, 0.41 in P2, and 0.34 in P3, highlighting the reduction in P.falciparum and predominance of $P$. vivax over the course of the study period. There was an increase in the number of municipalities with land settlement programs, but a slight increase in the mean number of families settled per municipality from P1 to P2, and a decrease in P3. In priority area Q2 as compared to Q1, the total deforested area in the municipalities was greater in P1 and P2 and smaller in P3 (Table 1).

Among the municipalities located in the low priority area for malaria control, there was an increase in the percentage of those with statistically significant autocorrelation, from $18(23.11 \%)$ in P1 to $33(47.71 \%)$ in P2 and $37(59,11 \%)$ in P3. These municipalities comprised a large geographic cluster with low API in P1 and P2 and two localized groups in P3, predominantly in the Southwest, Central-South, and Southeast of the State (Figure 3).

\section{Intermediate priority control area}

We observed two situations in the intermediate priority control area: (i) municipalities classified as Q3, i.e., with API above the mean and neighboring municipalities below it and (ii) those classified as Q4, i.e., with API below the mean and neighbors above it.

Municipalities in Q3 showed sharp decreases in API from one period to the next, especially from P2 to P3, similar to priority areas Q1 and Q2 (Table 2). There was a decrease in the number of municipalities classified in this area from P1 to P3 (6.32\% in P1, 3.97\% in P2, and $3.60 \%$ in $\mathrm{P} 3$ ). In P1, the majority of the municipalities located in Q3 were bordered on the State of Rondônia. In 
Figure 2

Stratification of priority malaria control areas based on the Local Moran (Box Map) Test. Mato Grosso State, Brazil, 1986-2003.

2a) $1986-1991$

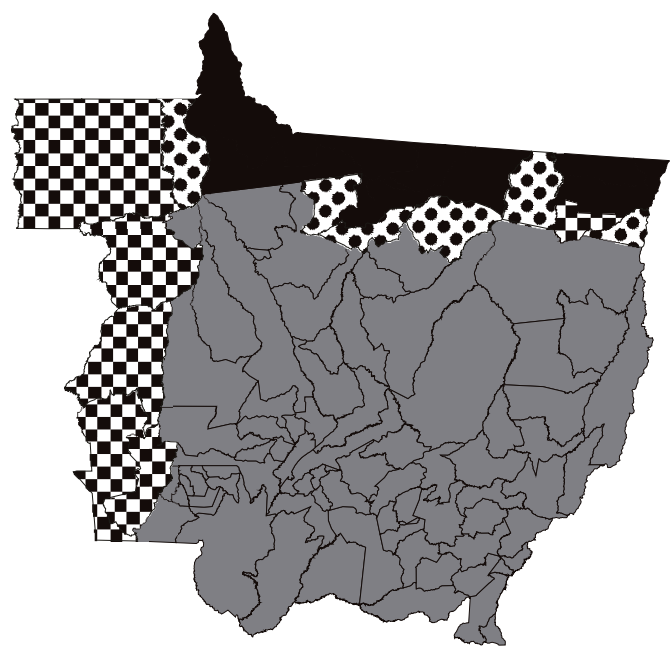

2b) 1992-1997

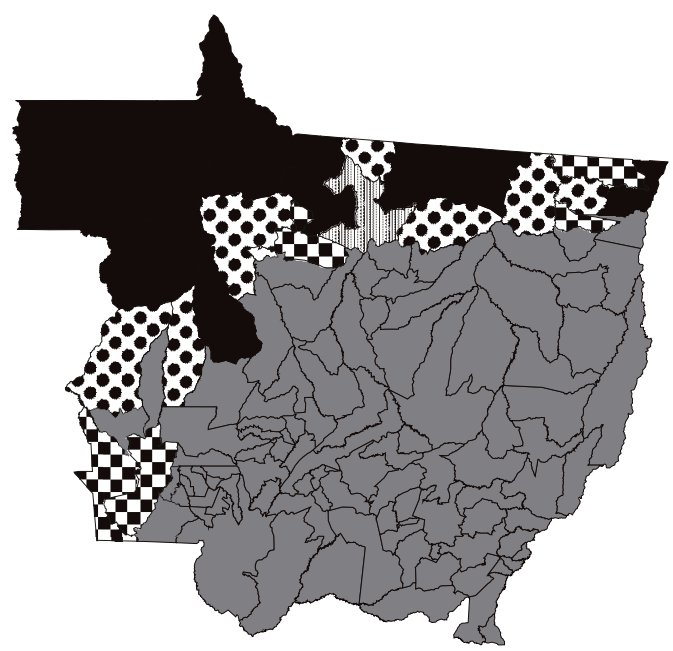

Quadrants of Moran scatterplot

Q $1(+/+)$

$\square$ Q2 (-/-)

Q Q3 (+/-)

[-. Q4 (-/+)

2c) $1998-2003$

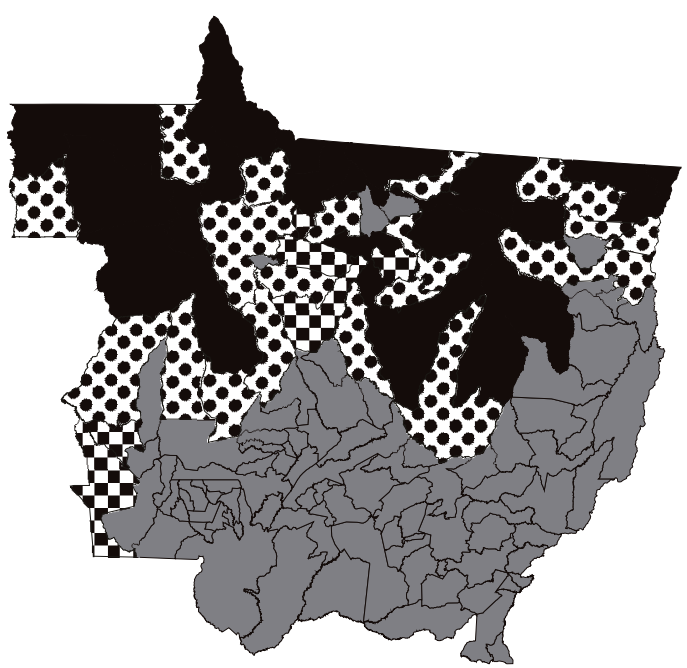

$w \frac{1}{s}$ 
High and low priority areas for malaria control generated by the Box Map, from 1986 to 2003, Mato Grosso State, Brazil.

\begin{tabular}{|c|c|c|c|}
\hline \multirow[t]{2}{*}{ Priority area/Characteristics } & \multicolumn{3}{|c|}{ Period } \\
\hline & 1986-1991 (P1) & 1992-1997 (P2) & 1998-2003 (P3) \\
\hline \multicolumn{4}{|l|}{ High control priority Q1 (+/+) } \\
\hline Number of municipalities (counties) & 10 & 18 & 27 \\
\hline \multicolumn{4}{|l|}{ Population variation (\%) } \\
\hline Minimum/maximum & $16.62 / 79.18$ & $-33.74 / 64.08$ & $-29.62 / 102.06$ \\
\hline Mean & 51.58 & 10.14 & 18.16 \\
\hline \multicolumn{4}{|l|}{ API (+ blood smears/1,000 inhabitants) } \\
\hline Minimum/maximum & $98.06 / 2,696.11$ & $56.38 / 995.64$ & $5.43 / 84.27$ \\
\hline Mean & 638.81 & 263.88 & 22.82 \\
\hline \multicolumn{4}{|l|}{ Moran Map (number of municipalities) } \\
\hline Non-significant & 5 & 8 & 21 \\
\hline$p \leq 0.05$ & 5 & 10 & 6 \\
\hline \multicolumn{4}{|l|}{ Number of families settled * } \\
\hline Number of municipalities & 3 & 13 & 18 \\
\hline Minimum/maximum & $152 / 718$ & $77 / 2,000$ & $50 / 2,004$ \\
\hline Mean & 373 & 659 & 642 \\
\hline \multicolumn{4}{|l|}{ Percentage of total area deforested ** } \\
\hline Minimum/maximum & $1.68 / 60.36$ & $3.17 / 48.30$ & $6.75 / 61.31$ \\
\hline Mean & 21.54 & 22.28 & 31.30 \\
\hline \multicolumn{4}{|l|}{ Low control priority Q2 (-/-) } \\
\hline Number of municipalities & 74 & 93 & 87 \\
\hline \multicolumn{4}{|l|}{ Population variation (\%) } \\
\hline Minimum/maximum & $-28.21 / 68.82$ & $-34.24 / 90.49$ & $-35.54 / 104.60$ \\
\hline Mean & 17.89 & 8.96 & 5.53 \\
\hline \multicolumn{4}{|l|}{ API (+ blood smears/1,000 inhabitants) } \\
\hline Minimum/maximum & $0.00 / 33.27$ & $0.00 / 31.41$ & $0.00 / 4.00$ \\
\hline Mean & 3.57 & 2.11 & 0.46 \\
\hline \multicolumn{4}{|l|}{ Moran Map (number of municipalities) } \\
\hline Non-significant & 54 & 62 & 53 \\
\hline$p \leq 0.05$ & 20 & 31 & 34 \\
\hline \multicolumn{4}{|l|}{ Number of families settled * } \\
\hline Number of municipalities & 14 & 35 & 44 \\
\hline Minimum/maximum & $17 / 2,406$ & $12 / 2,248$ & $14 / 948$ \\
\hline Mean & 367 & 392 & 259 \\
\hline \multicolumn{4}{|l|}{ Total percentage of deforested area ** } \\
\hline Minimum/maximum & $2.78 / 78.30$ & $4.10 / 92.31$ & $5.50 / 98.62$ \\
\hline Mean & 37.40 & 45.27 & 54.52 \\
\hline
\end{tabular}

API: Annual Parasite Index

* Calculation of the mean considered only municipalities with families settled by official government land settlement programs;

** Percentage of total land area deforested in the municipality in the years 1992, 1997, and 2003.

the subsequent periods, the Q3 municipalities were scattered around the entire State.

The Q3 pattern was different from that of intermediate priority area Q4, where the majority of the municipalities were neighbors of those with high and low control priority (Figure 2). In Q3, there was also a drop in P. falciparum and a predominance of $P$. vivax (the $P$. falciparum/P. vivax ratio dropped from 0.66 in $\mathrm{P} 1$ to 0.39 in $\mathrm{P} 2$ and 0.07 in P3). Population growth was higher in the municipalities in this area as compared to those in other priority areas, except for Q1 in P1 and Q4 in P2 (Tables 1 and 2).

We found an increase in the number of municipalities located in the Q4 intermediate priority area $(10.53 \%$ in $\mathrm{P} 1 ; 14.29 \%$ in P2; and $19.42 \%$ in P3) (Figure 2). Mean API in P2 (24.84 positive blood smears / 1,000 inhabitants) was higher than 
Figure 3

Stratification of priority malaria control areas based on the Local Moran (Moran Map). Mato Grosso State, Brazil, 1986-2003.

3a) $1986-1991$

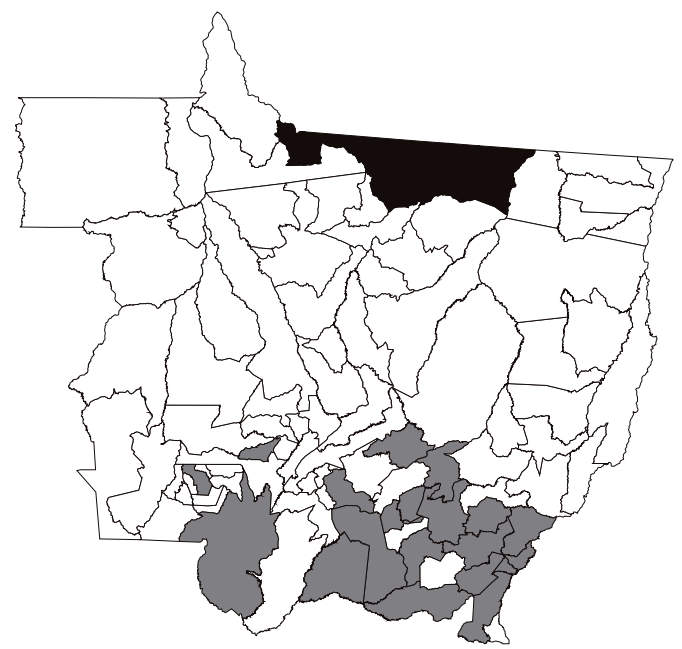

3b) 1992-1997

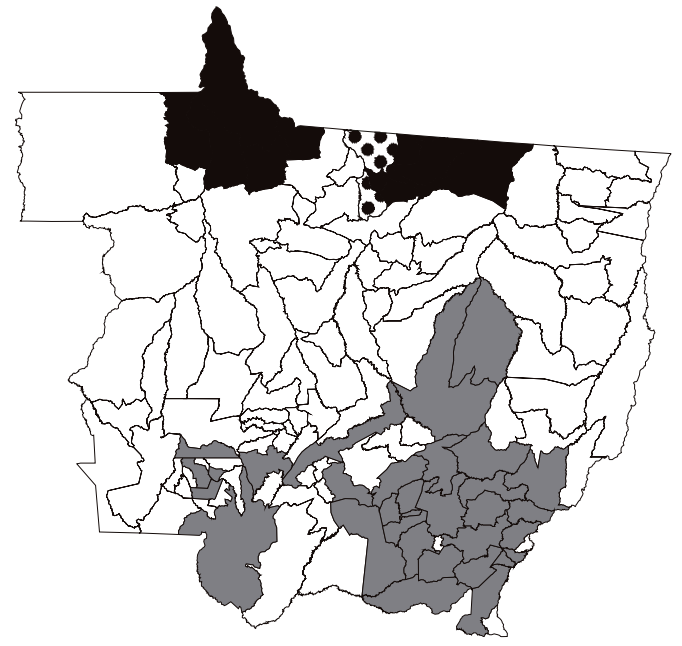

3c) $1998-2003$

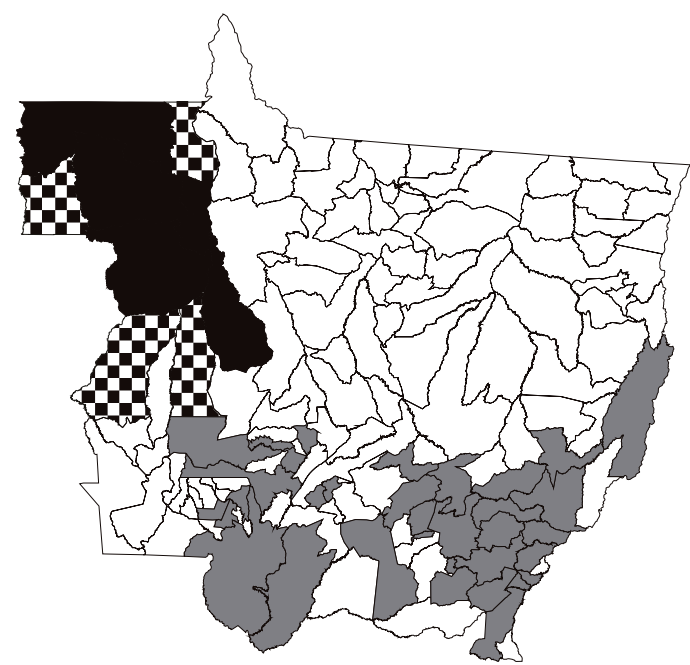

Quadrants of Moran scatterplot

$\mathrm{Q} 1(+/+)$

Q2 (-/-)

E. 03 (+/-)

be) $04(-/+)$

Non significant $w t_{s}^{N}$

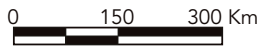


Intermediate priority areas for malaria control generated by the Box Map, 1986 to 2003, Mato Grosso State, Brazil.

\begin{tabular}{|c|c|c|c|}
\hline \multirow[t]{2}{*}{ Priority area/Characteristics } & \multicolumn{3}{|c|}{ Period } \\
\hline & 1986-1991 (P1) & $1992-1997$ (P2) & 1998-2003 (P3) \\
\hline \multicolumn{4}{|c|}{ Intermediate priority control area Q3 (+/-) } \\
\hline Number of municipalities (counties) & 6 & 5 & 5 \\
\hline \multicolumn{4}{|l|}{ Population variation (\%) } \\
\hline Minimum/maximum & $35.92 / 60.64$ & $-18.31 / 79.45$ & $-8.39 / 137.29$ \\
\hline Mean & 44.12 & 32.01 & 44.02 \\
\hline \multicolumn{4}{|l|}{ API (+ blood smears/1,000 inhabitants) } \\
\hline Minimum/maximum & $79.78 / 243.85$ & $45.36 / 60.85$ & $5.40 / 11.71$ \\
\hline Mean & 115.48 & 65.75 & 7.71 \\
\hline \multicolumn{4}{|l|}{ Moran Map (number of municipalities) } \\
\hline Non-significant & 6 & 5 & 5 \\
\hline$p \leq 0.05$ & 0 & 0 & 0 \\
\hline \multicolumn{4}{|l|}{ Number of families settled * } \\
\hline Number of municipalities & 3 & 4 & 1 \\
\hline Minimum/maximum & $185 / 527$ & $370 / 900$ & 236 \\
\hline Mean & 321 & 725 & 236 \\
\hline \multicolumn{4}{|l|}{ Percentage of total area deforested $* \star$} \\
\hline Minimum/maximum & $2.80 / 25.05$ & $16.45 / 40.13$ & $30.13 / 43.08$ \\
\hline Mean & 12.72 & 28.87 & 35.58 \\
\hline \multicolumn{4}{|c|}{ Intermediate priority control area Q4 (-/+) } \\
\hline Number of municipalities & 5 & 10 & 20 \\
\hline \multicolumn{4}{|l|}{ Population variation (\%) } \\
\hline Minimum/maximum & $14.02 / 52.00$ & $-4.69 / 228.94$ & $-14.31 / 142.10$ \\
\hline Mean & 31.30 & 37.97 & 22.12 \\
\hline \multicolumn{4}{|l|}{ API (+ blood smears/1,000 inhabitants) } \\
\hline Minimum/maximum & $0.39 / 66.34$ & $0.00 / 42.87$ & $0.00 / 5.16$ \\
\hline Mean & 18.89 & 24.84 & 2.35 \\
\hline \multicolumn{4}{|l|}{ Moran Map (number of municipalities) } \\
\hline Non-significant & 5 & 8 & 16 \\
\hline$p \leq 0.05$ & 0 & 2 & 4 \\
\hline \multicolumn{4}{|l|}{ Number of families settled * } \\
\hline Number of municipalities & 1 & 5 & 7 \\
\hline Minimum/maximum & 78 & $89 / 1,318$ & $42 / 450$ \\
\hline Mean & 78 & 755 & 376 \\
\hline \multicolumn{4}{|l|}{ Percentage of total area deforested $\star \star$} \\
\hline Minimum/maximum & $4.93 / 54.85$ & $9.67 / 69.98$ & $9.46 / 56.88$ \\
\hline Mean & 10.97 & 31.43 & 28.69 \\
\hline
\end{tabular}

API: Annual Parasite Index

* Calculation of the mean considered only municipalities with families settled by official government land settlement programs;

** Percentage of total land area deforested in the municipality in the years 1992, 1997, and 2003.

in P1 (18.89/1,000), dropping to 2.35/1,000 in P3 (Table 2). Unlike the previous two periods, in P3 the Q4 intermediate priority municipalities formed a mosaic, but concentrated in the North of the State (Figure 2).

In the Q4 intermediate priority municipalities, falciparum malaria predominated in $\mathrm{P} 1$, (with a $P$. falciparum/P. vivax ratio of 1.23 ) and decreased in P2 and P3 (falciparum/vivax ratios of 0.42 and 0.30 , respectively). The falciparum/ vivax ratio was higher in this area than in the high priority area, except in P2. Population growth was lower in Q4 than in Q3 (except in P2), but higher than in low priority municipalities (in all periods) and high priority ones (except in P1). The mean number of families settled was greater than in other areas in P2 and P3, except for the high priority area in P3. Among the Q4 municipalities, 
only two in P2 and four in P3 showed statistically significant spatial autocorrelation on the Moran Map (Figures 3b and 3c).

Considering the clustering of homogeneous priority control areas generated by the Box Map in $\mathrm{P} 1$, six municipalities located in the high priority area, 62 in the low priority area, and one in the Q3 intermediate priority remained in the same situation throughout the three periods. In the API spatial association dynamic for the municipalities according to priority area, three municipalities (Aripuanã, Juína, and Porto Alegre do Norte) were classified as intermediate priority Q3 and three (Itaúba, Juruena, and Marcelândia) as Q4 in $\mathrm{P} 1$ which were reclassified as high priority for transmission control in P3. The opposite situation was only true for the municipality of Pontes e Lacerda, which was in intermediate priority area Q3 in P1 but shifted to low priority in P3.

Importantly, in P1 the municipality of Colíder was located in the high priority area, but shifted to intermediate priority area Q4 in P2 and to low priority in P3. Another variation was that of Luciara, which was in Q4 in P1 (API = 27.95/1,000), low priority in $\mathrm{P} 2(1.83 / 1,000)$, and returned to intermediate priority Q4 in P3 $(1.85 / 1,000)$. Meanwhile, Nova Canaã do Norte was also located in Q4 (API = 66.34/1,000) in P1, shifted to high priority in P2 $(84.20 / 1,000)$, then shifted back to Q4 in P3 $(3.13 / 1,000)$.

\section{Discussion}

In Brazil, malaria control programs often adopt malaria transmission intensity (API) as the basic variable for stratifying priority control areas. Visual inspection of thematic maps based on this variable is considered simpler, and is commonly used by health programs and services to identify epidemiologically important areas and to select priority municipalities for intervention. However, this approach is limited to the boundaries of these municipalities, overlooking the possibility that the true priority area has a different configuration resulting from the influence of neighboring municipalities.

Since it fails to identify malaria's spatial correlation structure and does not deal with georeferenced data, mapping based on such stratification is insufficient to detect significant clusters and spatial patterns 17 . The need to know the disease's spatial association considering the neighboring municipalities, i.e., to establish an association between the occurrence of malaria in a given municipality and that in neighboring municipalities, is based on recognition of the close association between malaria and environmental, economic, and social factors, which frequently extrapolate geographic boundaries defined by political and administrative criteria.

The use of spatial analysis as a tool changed the configuration of the risk area for malaria in the State of Mato Grosso. The Box Map allowed identifying the spatial dynamics of malaria distribution and spatial association areas for API in different time periods, considering the occurrence of the disease in neighboring municipalities.

Each area with positive or negative spatial association included municipalities with statistically significant spatial autocorrelation. This autocorrelation, visualized with the Moran Map, indicated geographic clusters with extreme values, i.e., high incidence in the high priority area $(\mathrm{Q} 1+/+)$; no or low incidence in low priority areas (Q2 - /-), and a sharp difference in API between the municipality and its neighbors in the case of intermediate priority Q4 (-/+). Identification of these areas points to different risks for malaria transmission which in practice are not limited by the borders of the municipality. Clustering of similar municipalities using spatial analysis rules out spatial randomness in the distribution of the disease and allows classifying differentiated malaria control priority areas. Thus, the higher priority areas with significant spatial autocorrelation can be considered critical, possibly encompassing municipalities experiencing a full-blown malaria epidemic process and which would be chosen for concentrating interventions in the form of campaigns.

The observed differences between high, low, and intermediate priority areas point to distinct processes in malaria occurrence (Tables 1 and 2). Indicators like population variation, number of families settled, percentage of total area deforested, and year in which the municipalities were incorporated provide clues as to the dynamics involved in these areas, thus aiding the understanding of different malaria patterns. The variables point to different stages in land occupation, allowing the identification of distinct characteristics between priority areas and between periods.

Between the first and last periods, in high priority area Q1 there was a decrease in API and an increase in the number of municipalities, indicating specific malaria transmission dynamics: epidemic malaria in $\mathrm{P} 1$, a transition from epidemic to endemic in P2, and an endemic process in P3 with the persistence of some epidemic foci. The clusters identified by the Moran Map in the high priority area during the three periods (based on API and prevalence of P. falciparum malaria) constituted a critical area requiring special intervention. The malaria control activities in these locations were intensive and targeted. 
During the 1980s, part of the period included in P1, the agricultural frontier was extended in the State of Mato Grosso, establishing close connections between spatial occupation and social (re)organization. Recent settlements and the form of exploitation of natural resources were characterized by instability in land use in the State, especially in the North 18 . In P1, the intense migratory flow in the high priority area, as expressed by heavy population growth (52\%), resulted from the discovery of placer gold in the Peixoto Azevedo Valley. There was an initial influx of pan miners from the North and Northeast of Brazil, who were later followed by Southern Brazilians, who used pan mining to complement their farming income. Agricultural settlement programs further intensified the population mobility caused by pan mining. The influx was small if one considers only the government settlement programs, with an average of 373 families settled per municipality, but during this same period there was an intense settlement process sparked by private projects and a large influx of spontaneous migrants.

The demographic and API variation in this area may have been even greater than reflected in the official statistics, considering the gold rush involving small pan mining operations. The great human mobility involved in pan mining makes the census and disease records rather imprecise, failing to compile the typically large population fluctuation in this economic activity. The incipient health services infrastructure and difficulties in access to diagnosis and treatment also certainly contributed to the underestimation of malaria transmission.

In P2, some municipalities that had been classified in the high priority area were now characterized as in a transition, probably due to the shift in land use from mining to agriculture and cattle-raising 19. This period of changes in land use characteristics also involved demographic changes, with a slowdown in population growth and an increase in the average number of families settled by official government programs (Table 1). Considering the spatial dynamics, two distinct geographic clusters were identified in the high priority area, referred to here as Cluster 1 and Cluster 2, expressing the shift in the so-called "pioneer waves" 20 towards the Northwest of the State (Figures 2b and 2c).

The area in Cluster 1 coincides with the region known as "Nortão" or the "Big North", located in the Peixoto de Azevedo River Valley in the Central-North of Mato Grosso19, traversed by the BR-163 Highway (Cuiabá-Santarém). During the 1990s, there was a mass population exodus from the municipalities comprising Cluster 1, as shown by the population growth variation: $66.10 \%$ in $\mathrm{P} 1$, $1.90 \%$ in P2, and $5.13 \%$ in P3. Duarte \& Fontes 21 attributed the drop in malaria cases in this area mainly to the shift away from pan mining.

Despite the evidence for a drastic reduction in API in high priority area Q1 beginning in P2, malaria was still a problem in P3. The predominance of vivax malaria indicates a process of malaria endemization in the area, although the levels were still higher than in the low priority area. The higher incidence of malaria may have been due to the new agricultural settlements. Meanwhile, the epidemic focus identified by the Moran Map in P3 is related to the occupation of new areas for agricultural development, with a combination of factors like pan mining operations, lumbering, and farm settlements or makeshift camps (land occupation not legally recognized by the National Institute for Colonization and Agrarian Reform, INCRA).

However, in many cases the people left over from (or left out of) the official settlement programs constituted roving groups of intermittent or seasonal workers, who shifted between the cyclical activities involved in agricultural production 22, mining, and/or lumbering, thereby feeding the internal migratory flow. The spatial interaction (access routes, physical proximity, and human mobility) between pan mining operations, farm settlement areas, cattle-raising, and cities is a highly dynamic element in malaria prevalence in the high priority area 18,19 and possibly also in the lower priority area, considering the imported cases.

Unlike the high priority area, the lower priority areas are classified as having low endemicity. Even so, they also showed a decrease in API from $\mathrm{P} 1$ to P3. Comparing the three periods, there was a decrease in the number of low priority municipalities. Importantly, most of the low priority municipalities were incorporated before 1986. This suggests greater stability in the land occupation process, as indicated by: an important number of municipalities with no reports of malaria cases; municipalities with low API; smaller population growth; larger deforested area; lower mean number of families settled per municipality; and predominance of vivax malaria.

Another important process in the lower priority municipalities was the increase in the mean size of farm operations, suggesting the absorption of small farming and cattle-raising operations into the formation of new latifundia 23 , central to major commercial cash crops like soybeans, cotton, and sugar cane. The development of technology-intensive agriculture and cattle-raising, greater demographic concentration, and implementation of urban infrastructure characterized 
the lower priority area 24 . The cases reported in this region may have been related to the population flow of cases imported from other regions in Mato Grosso or another State.

The intermediate priority area (Q3 and Q4) presupposes a transition from the high to the low priority area. This can be observed in the dynamics of municipalities that were classified as intermediate priority Q4 in P1 and shifted to high priority in P3. The situation can also be the opposite, i.e., municipalities in intermediate priority area Q3 or Q4 in P1 or P2 that evolved to lower priority in P3 (Figures 1b, 2b, and 3b).

The municipalities located in intermediate priority areas Q3 and Q4 can be considered more vulnerable to malaria, considering the high population growth, smaller deforested area, and important number of families settled. The change in priority stratification of some municipalities from one period to another mainly suggests the influence of neighboring municipalities in the dynamics of malaria distribution. Different stages in the land occupation process and/or organization of health services probably have an impact on these dynamics.

Meanwhile, the municipalities located along the border of the State of Rondônia and identified as intermediate priority Q3 in P1 might have assumed a different configuration if the study had included malaria records from that State. Municipalities in transition should thus be interpreted cautiously, given the complexity of internal and external factors at play.

Thus, the visualization of municipalities by risk strata, as adopted by the Health Surveillance Secretariat of the Ministry of Health (SVS/MS), is commonly used by health services to identify epidemiologically important malaria areas. Although such mapping is useful for prioritizing municipalities and developing strategic activities and allocating resources, it fails to take into account the spatial dynamics involved in malaria transmission, often extrapolating these contours and mutually influencing other areas in the State and country. Analyzing the disease in terms of it spatial/temporal processes expands the mapping's visual perspective.

Spatial analysis has been used in malaria studies in the last two decades as an important tool to locate risk areas and identify associated factors in order to orient control activities, including transfer of funds. The priority stratification used in the current study identified the priority areas encompassing municipalities and their neighbors and can thus become an important resource to back the central and regional health levels in planning control, monitoring, and evaluation activities. Moran's I spatial statistics and the Box Map are quite well known and widely used in spatial analysis work, and are also easy to interpret ${ }^{25}$. Given the progress in computer programs for spatial analysis and mapping (especially free access programs) and the improvement in the SIVEPMalaria databank, geoprocessing can become an important tool for demarcating risk areas, taking neighboring municipalities into account.

The spatial analysis methodology used here is not restricted to the limited risk presentation for each single municipality, but allows determining priority control areas that contemplate the dynamics of the epidemic/endemic beyond its narrowly defined political/ administrative borders. It thus reinforces the potential of spatial analysis to detect differentiated priority situations for malaria control. Knowledge of spatial dynamics allows malaria surveillance actions that consider the various factors involved in transmission in the municipalities and their neighbors. Spatial analysis, specifically the Box Map and Moran Map, proved relevant and should be evaluated in future research, compared to the current methodology used by the Ministry of Health to define risk areas and allocate funds for malaria control. 


\section{Resumo}

Pautado em técnicas de análise espacial, analisou-se a estratificação de áreas prioritárias para controle da malária no Estado de Mato Grosso, Brasil. Trabalhouse Incidência Parasitária Anual, relação Plasmodium falciparum/Plasmodium vivax, variação populacional, número de famílias assentadas e percentuais da área desmatada. Foram utilizados os testes de I de Moran e Moran Local, visualizadas pelo Box Map e Moran Map, nos períodos de: 1986 a 1991, 1992 a 1997 e 1998 a 2003. Pelo Box Map identificaram-se áreas de prioridade maior, menor e intermediária, e pelo Moran Map localizaram-se municípios com autocorrelação estatisticamente significante. Na área de maior prioridade, localizada na região norte mato-grossense, a incidência reduziu drasticamente apesar do aumento do número de municípios de primeiro a último período. A área de menor prioridade agregou municípios da região sudeste, sudoeste e centro-sul. A área de prioridade intermediária localizou-se na fronteira com estados vizinhos e entre os municípios de maior e menor prioridade. A análise espacial apontou a importância da vizinhança na determinação de áreas de prioridade, constituindo em importante ferramenta para a vigilância e controle de malária.

I de Moran; Malária; Controle de Doença Transmissíveis; Análise Espacial

\section{References}

1. Atanaka-Santos MA, Souza-Santos R, Czeresnia D, Oliveira RM. Comportamento epidemiológico da malária no Estado de Mato Grosso, 1980-2003. Rev Soc Bras Med Trop 2006; 39:187-92.

2. Barata RB. Malária e seu controle. São Paulo: Editora Hucitec; 1998.

3. Greenwood BM. The microepidemiology of malaria and its importance to malaria control. Trans R Soc Trop Med Hyg 1989; 83:525-9.

4. Loiola CCP, Silva CSM, Tauil PL. Controle da malária no Brasil: 1965 a 2001. Rev Panam Salud Pública 2002; 11:235-44.

5. Superintendência de Campanhas de Saúde Pública. Relatório de atividades da SUCAM, 1981. Brasília: Superintendência de Campanhas de Saúde Pública; 1982.

6. Rede Interagencial de Informações para a Saúde. Indicadores básicos de saúde no Brasil: conceitos e aplicações. Brasília: Organização Pan-Americana da Saúde; 2002.

7. Organización Panamericana de la Salud. Informe de la situación de los programas regionales de malaria en las Américas: con base en datos de 2000 . Washington DC: Organización Panamericana de la Salud; 2001.

\section{Contributors}

M. Atanaka-Santos participated in the data collection and analysis, discussion of the results, and literature review. R. Souza-Santos and D. Czeresnia collaborated in the analysis and discussion of the results. All the authors contributed to the study design and drafting of the final article.
8. Bailey T, Gatrell A. Spatial data analysis by example. London: Longman; 1995.

9. Chaves SS, Rodrigues LC. An initial examination of the epidemiology of malaria in the State of Roraima, in the Brazilian Amazon Basin. Rev Inst Med Trop São Paulo 2000; 42:269-75.

10. Secretaria do Estado de Planejamento e Coordenação Geral. Anuário estatístico de Mato Grosso. Cuiabá: Secretaria do Estado de Planejamento e Coordenação Geral; 2000.

11. Secretaria do Estado de Planejamento e Coordenação Geral. Anuário estatístico de Mato Grosso. Cuiabá: Secretaria do Estado de Planejamento e Coordenação Geral; 2001.

12. Secretaria do Estado de Planejamento e Coordenação Geral. Anuário estatístico de Mato Grosso. Cuiabá: Secretaria do Estado de Planejamento e Coordenação Geral; 2002.

13. Secretaria do Estado de Planejamento e Coordenação Geral. Anuário estatístico de Mato Grosso. Cuiabá: Secretaria do Estado de Planejamento e Coordenação Geral; 2003.

14. Secretaria do Estado de Planejamento e Coordenação Geral. Anuário estatístico de Mato Grosso. Cuiabá: Secretaria do Estado de Planejamento e Coordenação Geral; 2004. 
15. Cliff AD, Ord JD. Spatial processes: model and application. London: Pion; 1981.

16. Câmara G, Carvalho MS, Cruz OG, Correa V. Análise espacial de áreas. In: Druck S, Carvalho MS, Câmara G, Monteiro AMV, organizadores. Análise espacial de dados geográficos. Brasília: Empresa Brasileira de Pesquisa Agropecuária; 2004. p. 157209.

17. Santos SM, Barcellos C, Carvalho MS. Análise ecológica da distribuição e contexto socioespacial dos homicídios. Porto Alegre: Organização Pan-Americana da Saúde; 1991.

18. Barbieri AF. População, saúde e uso da terra: avaliação da prevalência de malária em uma região da Amazônia Brasileira. In: Seminário Brasileiro de Demografia da IUSSP. http://www.abep.org. br/usuario/GerenciaNavegacao.php?caderno $\mathrm{id}=362 \&$ nivel=1\&texto_id=2089 (accessed on 30/ Aug/2005).

19. Barbieri AF, Soares Filho BS, Coelho LC. Uso da terra e malária: uma análise espacial para o Norte de Mato Grosso. In: Encontro Nacional de Estudos Populacionais da ABEP, 12. http://www.abep.nepo.unicamp.br/docs/anais/pdf/2000/Todos/ambt15_1.pdf (accessed on 30/Aug/2005)

20. Martins JS. O tempo da fronteira: retorno à controvérsia sobre o tempo histórico da frente de expansão e da frente pioneira. Tempo Social - Revista de Sociologia da USP 1996; 8:25-70.
21. Duarte EC, Fontes CJF. Associação entre a produção anual de ouro em garimpos e incidência de malária em Mato Grosso - Brasil, 1985-1996. Rev Soc Bras Med Trop 2002; 35:665-8.

22. Nájera JA. Problemas relacionados con modificaciones del medio ambiente y con la ecología humana. In: Reunión de Directores de los Servicios Nacionales de Erradicación de la Malaria en las Américas. Washington DC: Organización Panamericana de la Salud/Organización Mundial de la Salud; 1981. (Publicación Científica, 405).

23. Andrade MP. Estrutura fundiária, modernização e distribuição de renda na agricultura matogrossense [Master's thesis]. Piracicaba: Escola Superior de Agricultura Luiz de Queiroz, Universidade de São Paulo; 1989.

24. Guimarães EN, Leme HJC. Caracterização histórica e configuração espacial da estrutura produtiva do centro-oeste. In: Hogan DJ, Carmo RL, Cunha JMP, Baeninger R, organizadores. Migração e ambiente no Centro-oeste. Campinas: Editora Unicamp; 2002. p. 17-85.

25. Dias PRTP, Nobre FF. Análise dos padrões de difusão espacial dos casos de AIDS por Estados brasileiros. Cad Saúde Pública 2001; 17:1173-87.

Submitted on $31 / \mathrm{Jan} / 2006$

Final version resubmitted on 30/Oct/2006 Approved on 06/Nov/2006 